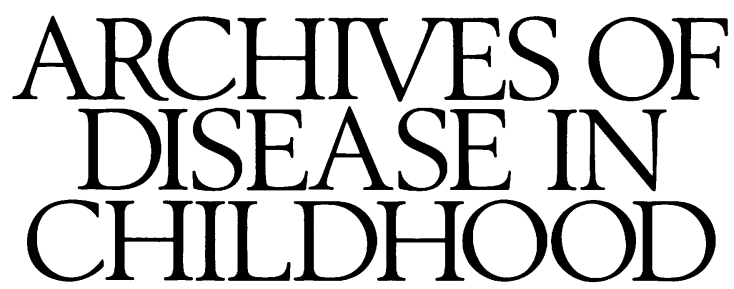

\title{
Do chesty children become chesty adults?
}

The possible links between experiences in childhood and disease in adult life have become topical in recent years. ${ }^{1}$ The suggestion that chest illness in childhood may contribute to the development of chronic respiratory problems in middle and old age, however, has intrigued researchers for at least two decades. ${ }^{2}$ Two chronic respiratory conditions of childhood, asthma and bronchiectasis, provide rather different models for such a link between childhood and adult disease.

\section{Childhood asthma, adult asthma, and chronic airflow obstruction}

Few studies provide prospective information on the long term prognosis of childhood asthma. Blair followed up 267 children who had attended his east London general practice with asthma under 12 years of age. ${ }^{3}$ Twenty years later, one half had mild or no asthmatic symptoms but $21 \%$ had remained symptomatic throughout adolescence, and a further $27 \%$ had relapsed after at least three years free of symptoms. Relapse often occurred in the late teens, highlighting the problems of determining prognosis from many of the earlier clinical series with shorter periods of follow up. ${ }^{3}$

Population based data are provided by the ongoing follow up of British births during one week in $1958 .{ }^{4}$ Among 1899 children with a history of asthma or wheezy bronchitis ascertained at 7 years of age, $10 \%$ reported asthma or wheezy bronchitis in the past year at 23 , and a further $10 \%$ recalled an attack since their 16th birthday. These figures compare with $3 \%$ and $4 \%$, respectively, for 8658 subjects with no history of wheezing illness in early childhood.

The most comprehensive information on the natural history of childhood asthma is provided by the follow up of 323 wheezy children in Melbourne, Australia, who were most recently examined at 28 years of age. ${ }^{5}$ Three quarters of the wheezy children identified in the population at 7 years of age had ceased to wheeze by age 14. Nearly half of this group reported wheeze in the past three years at age 28 years, but less than $10 \%$ had attacks more than once a week. Two thirds of the 47 children with frequent or unremitting childhood asthma (often associated with an early onset) continued to have attacks of wheeze more than once a week at age 28 , and only one had become asymptomatic. The outcome among children with less frequent attacks at age 14 was intermediate: over $80 \%$ continued to wheeze, but only one third had weekly attacks. Symptoms had worsened in over one third of those with no or infrequent wheezing at 21 years of age.

Together, these studies confirm that some wheezy children continue to wheeze as young adults, although the proportion that 'grow out' of their asthma differs considerably between studies, probably due to different methods of identifying wheezing attacks. The tendency for symptoms to relapse after periods of partial or complete remission emphasises the chronic nature of the condition. What is unknown is how an active or latent wheezing tendency in the 20 s relates to asthma and chronic airflow limitation in middle and old age.

There is some evidence that a diagnosis of asthma, ${ }^{67}$ or non-specific bronchial reactivity, ${ }^{89}$ are risk factors for more rapid decline of ventilatory function in middle age, but the interpretation of such findings is complex. Both bronchial reactivity and rapid functional decline are associated with low initial values for spirometric indices, and the causeeffect relationships among these three features are unclear. Other data suggest that adult asthmatics do not have accelerated rates of lung function decline. ${ }^{10}$

\section{Lower respiratory tract infection, chronic bronchitis, and} emphysema

Although bronchiectasis is declining as a clinical and public health problem, ${ }^{11}$ its onset after severe episodes of pneumonia, even in the previously healthy child, provides a basis for the concept that frequent lower respiratory tract infections in early childhood might result in subclinical damage to the lung that later manifests itself in chronic phlegm production and, perhaps, airways obstruction. It has been pointed out, however, ${ }^{12}$ that 'lung damage' due to childhood chest illness does not readily fit with current concepts of the pathogenesis of pulmonary emphysema, which is probably the major determinant of chronic airflow limitation and mortality from chronic respiratory disease in middle age.

The suggestion that chronic bronchitis might have its origins in childhood was originally prompted by epidemiological observations that respiratory mortality and morbidity in both childhood and adult life showed similar variations between countries, regions of Britain, urban and rural areas, and socioeconomic groups. ${ }^{2}$ More recently, a striking geographical correlation has been described between respiratory mortality among infants during 1921-5, and adult mortality attributed to chronic bronchitis during $1968-78$ in England and Wales. ${ }^{13} \mathrm{Few}$ studies have addressed the effect 
of migration between low and high risk areas, which would clarify the relevance of the geographical patterns to the 'childhood origins' hypothesis. National servicemen recruited from industrial areas carried an increased risk of admission for respiratory disease, however, regardless of the region to which they were posted. ${ }^{14}$

At the individual level, both retrospective and prospective studies support a link between childhood chest illness and respiratory problems in adults. There has been little new evidence published since the subject was comprehensively reviewed in 1983. ${ }^{12}$ The longest established prospective study is based upon the British 1946 birth cohort. ${ }^{1516}$ The association between chronic winter cough and a history of bronchitis or pneumonia in early childhood, which had been found at ages 20 and 25, was confirmed at 36 years of age. After adjustment for smoking, housing tenure, and domestic crowding in childhood, the prevalence of winter cough among 828 children with a history of respiratory illness by age 10 was $10 \cdot 5 \%$, compared with $7 \cdot 4 \%$ among the 2254 with no such history. ${ }^{15}$ The corresponding mean adjusted peak expiratory flow rates (PEFR) were $475 \mathrm{l} / \mathrm{min}$ and $485 \mathrm{l} / \mathrm{min}$. Mean adjusted PEFR was also lower among the 1695 children with a history of whooping cough by age 10 , but chronic cough was less common in this group. ${ }^{16}$

The nature of the childhood illnesses labelled as 'bronchitis' in this and other studies is unclear, and many may have been related to asthma. ${ }^{17}$ In both the Melbourne study ${ }^{18}$ and the British 1958 cohort, ${ }^{4}$ adults in their 20 s who recalled recent attacks of asthma or wheeze also appeared to be at considerably increased risk of chronic cough and phlegm production, among both smokers and non-smokers. In the 1958 cohort, the association betweeen chest illness in childhood and chronic cough or phlegm at age 23 was almost entirely attributable to persistence of a wheezing tendency. ${ }^{4}$ Ventilatory function tests have not yet been performed in this cohort, but as wheezy young adults have lower mean levels of forced expiratory volume in one second ${ }^{5}$ and PEFR, ${ }^{15}$ it seems likely that at least part of the association between childhood chest illness and reduced levels of ventilatory function in adults ${ }^{6} 1519$ may be related to the chronic manifestations of asthma.

Studies relying upon retrospective ascertainment of childhood disease must be interpreted with caution, but it is pertinent to note that in one, the respiratory problems in childhood which were associated with adult obstructive airways disease were those in the category of 'chronic or recurrent airway disease', rather than 'severe acute respiratory illness'. ${ }^{19}$ The former group had a more adverse outcome, however, even when those with a diagnosis of asthma in childhood or adulthood were excluded from the analysis. 19

\section{Conclusion}

Clearly, much remains to be clarified about the natural history of asthma and its associations with other respiratory disorders in children and adults, but potentially it could have a central role in explaining continuities of respiratory morbidity between childhood and later life. The suggestion that acute lower respiratory tract infections in childhood may be a cause of airways obstruction in adulthood remains one of the most intriguing and elusive epidemiological hypotheses spanning, as it does, from infancy to late middle age, and from one poorly defined disease category to another. ${ }^{20}$ Nevertheless, its solution may be of considerable importance in evaluating the public health burden posed by the extremely common, but often self limiting, respiratory illnesses of early childhood.

Department of Clinical Epidemiology and Social Medicine,

D P STRACHAN

St George's Hospital Medical School,

Cranmer Terrace, London SW17 ORE

1 Barker DJP. Childhood causes of adult diseases. Arch Dis Child 1988;63: 867-9.

2 Reid DD. The beginnings of bronchitis. Proc $R$ Soc Med 1969;62:311-6.

3 Blair H. Natural history of childhood asthma. 20-year follow-up. Arch Dis Child 1977;52:613-9.

4 Strachan DP, Anderson HR, Bland JM, Peckham C. Asthma as a link between chest illness in childhood and chronic cough and phlegm in young adults. Br Med f 1988;296:890-3

5 Kelly WJW, Hudson I, Phelan PD, Pain MCF, Olinsky A. Childhood asthma in adult life: a further study at 28 years of age. $\mathrm{BrMed} \mathcal{F}$ 1987;294:1059-62. in adult life: a further study at 28 years of age. Br Med f 1987;294:1059-62. bronchitis and emphysema. An 8-year study of working men in London. bronchitis and emphysema. An 8-year s

7 Brown PJ, Greville HW, Finucane KE. Asthma and irreversible airflow obstruction. Thorax 1984;39:131-6.

8 Barter CE, Campbell AH. Relationship of constitutional factors and cigarette smoking to decrease in 1-second forced expiratory volume. Am Rev Respir Dis 1976;113:305-14.

9 Taylor RG, Joyce H, Gross E, Holland F, Pride NB. Bronchial reactivity to inhaled histamine and annual rate of decline of FEV 1 in male smokers and ex-smokers. Thorax 1985;40:9-16.

10 Burrows B, Bloom JW, Traver GA, Cline MG. The course and prognosis of different forms of chronic airways obstruction in a sample from the general population. N Engl F Med 1987;317:1309-14.

11 Barker AF, Bardana EJ. State of the art. Bronchiectasis: update of an orphan disease. Am Rev Respir Dis 1988;137:969-78.

12 Samet JM, Tager IB, Speizer FE. The relationship between respiratory illness in childhood and chronic air-flow obstruction in adulthood. Am Rev Respir Dis 1983;127:508-23.

13 Barker DJP, Osmond C. Childhood respiratory infection and adult chronic bronchitis in England and Wales. Br Med f 1986;293:1271-5.

14 Rosenbaum $S$. Home localities of national servicemen with respiratory disease. British Fournal of Preventive and Social Medicine 1961;15:61-7.

15 Britten N, Davies JMC, Colley JRT. Early respiratory experience and subsequent cough and peak expiratory flow rate in 36 year old men and women. $\mathrm{Br}$ Med $\mathcal{F}$ 1987;294:1317-20.

16 Britten N, Wadsworth J. Long term respiratory sequelae of whooping cough in a nationally representative sample. $\mathrm{Br} M e d \mathrm{~F}$ 1986;292:441-4.

17 Phelan PD. Does adult chronic obstructive airways disease really begin in childhood? Br 7 Dis Chest 1984;78:1-9.

18 Martin AJ, Landau LI, Phelan PD. Asthma from childhood at age 21: the patient and his disease. $\mathrm{Br} \mathrm{Med} \mathcal{F}$ 1982;284:380-2.

19 Burrows B, Knudson RJ, Lebowitz MD. The relationship of childhood respiratory illness to adult obstructive airways disease. Am Rev Respir Dis 1977;115:751-60.

20 Holland WW. The beginnings of bronchitis. Thorax 1982;37:401-3. 